\title{
Interactive Mobile Presentation of Textiles
}

\author{
Pawel M. Orzechowski \\ TextureLab, Heriot Watt University \\ Edinburgh, Scotland \\ (44) 1314514166 \\ po38@hw.ac.uk
}

\begin{abstract}
While shopping online for textiles from a mobile device, we face the perceptual gap between qualities we can perceive via the interface and those we sense when handling the real textile product. In this research I first investigate the qualities that people look for when interacting with textiles. Further, I examine the gestures people commonly use to handle fabrics, and I propose a way to imitate them on a mobile device. Finally, I prototype touch-screen interactive-video interfaces and assess best practice.
\end{abstract}

Categories and Subject Descriptors: D.3.3H.5.2 [User Interfaces]: Graphical User Interfaces, Input devices and Strategies, User Centered Design

General Terms: Design, Human Factors

Keywords: Textiles, interactive video, perception, mobile devices, gestures.

\section{BACKGROUND AND APPROACH}

The language of perceived textile qualities and relationships between them can be applied for communication, decisionmaking and collaboration. Professional textile related organisations develop their own methodologies and taxonomies (Kawabata system, AATCC standards, etc.). Non-professionals when asked to handle fabrics in studies are usually trained in using similar professional terms [5]. However, to evaluate an interface for untrained English speakers, a relevant, intuitive, unprofessional taxonomy is needed. This can be obtained from fabric handling and word sorting studies.

Adding interactivity to the video can make shopping online for fabrics feel more enjoyable and less risky [2]. Common sources of risk are disparity of features in purchased and delivered product and associated hassle of product exchange. Interactive video aims to minimise that risk in a way pleasant to the shopper. Further experiments will compare feature extraction while handling real fabrics versus video, looking for an improvement of perceived risk, see-touch-handle and enjoyment [3].

When designing life-based gestures, both geometrical and intentional/expressive elements need to be considered [1]. The professional gestures for handling textiles are unlikely to be widely used, so their natural counterparts were studied and digitised.

\section{RESEARCH QUESTIONS}

Can a non-professional taxonomy of textile qualities be derived and used for mobile interface evaluation?

Does adding multi-touch interaction feedback to video make it a more natural and more engaging means of communicating fabric qualities?

Do new movement inspired gestures (stroking, stretching,

Copyright is held by the author/owner(s).

MobileHCI 2010 September 7-10, 2010, Lisboa, Portugal.

ACM 978-1-60558-835-3/10/09. crunching, etc.) improve perception of qualities from interactive videos?

\section{PROGRESS AND PLANS}

A taxonomy of 78 words used by non-professionals to describe fabric qualities was derived from fabric handling and word sorting studies. Three studies with 30 on-site and 140 online participants resulted in a final set of words and their relationships.

A natural gesture interactive video is being developed for iPad and iPhone, based on the analysis of participants gestures in fabric handling study. Four hundred minutes of video were annotated and common clusters of gestures are now being translated into multi-touch finger operated touch-screen gestures. The iPhone application being developed combines those gestures with stopmotion images of moving textiles (processed with shoogleit.com[4]). This application will help to measure the difference in perceived qualities and judgements of digital versus real textile.

\section{CONTRIBUTION TO MOBILE HCI}

We investigated novel mobile interfaces that create a similar perceptual experience to handling a physical swatch of fabric textile material that is complex, flexible and deformable, hence difficult to communicate digitally. Findings on ways to manipulate swatches to get tactile feedback, reflection and surface texture clues can be used to design and evaluate new mobile interfaces. Finally with understanding the rationale behind particular gestures it will be possible to influence shopping behaviour with simple visual, sound and haptic interface clues.

\section{ACKNOWLEDGMENTS}

This project is a part of CTEX and Digital Sensoria.

\section{REFERENCES}

[1] Hummels, C., Overbeeke, K. C., \& Klooster, S. (2007). Move to get moved: a search for methods, tools and knowledge to design for expressive and rich movement-based interaction. Pers Ubiquit Comput, 677-690.

[2] Lee, H.-H., Kim, J., \& Fiore, A. M. (2010). Affective and Cognitive Online Shopping Experience. Clothing and Textiles Research Journal, 140-154.

[3] Levin, A. M., Levin, I. P., \& Heath, C. (2003). Product category dependant consumer preferences for online and offline shopping features and their influence on multi-channel retail alliances. Journal of Electronic Commerce Research, 8593.

[4] Padilla, S. (2010, May 26). Retrieved May 26, 2010, from ShoogleIt: www.shoogleit.com

[5] Philippe, F., Schacher, L., Adolphe, D. C., \& Dacremont, C. (2003). The sensory panel applied to textile goods - a new marketing tool. Journal of Fashion Marketing and management, 235-248. 